\title{
Micro-Algal Bioproducts a Growing Universe
}

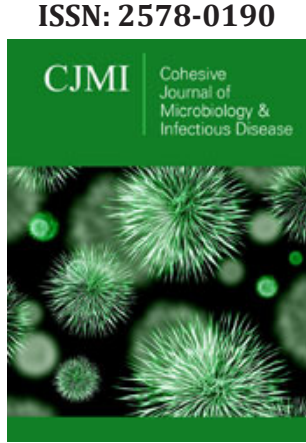

${ }^{* 1}$ Corresponding author: Leonardo Brantes Bacellar Mendes, Petrobras Research and Development Center, Brazil

Submission: 漈 May 07, 2018

Published: 淟 May 16, 2018

Volume 2 - Issue 4

How to cite this article: Leonardo Brantes Bacellar Mendes, Micro-Algal Bioproducts a Growing Universe. Cohesive J Microbiol Infect Dis. 2(4). CJMI.000545.2019. DOI: 10.31031/CJMI.2019.02.000545

Copyright@ Leonardo Brantes Bacellar Mendes, This article is distributed under the terms of the Creative Commons Attribution 4.0 International License, which permits unrestricted use and redistribution provided that the original author and source are credited.

\author{
Leonardo Brantes Bacellar Mendes*
}

Petrobras Research and Development Center, Brazil

\section{Editorial}

Cultivating microalgae from relatively simple chemical compounds and incident sunlight does not just require luck. It involves a great deal of scientific knowledge about the species chosen and the dynamic influences that biotic and abiotic factors exert on crop stability and productivity over extended periods of time. The consequences of the efforts employed in highly specialized labor and capital in general originate from the production of biomass obtained and its quality control. Microalgae biomass with high nutritional quality is usually destined to feed larvae used in aquaculture such as shrimp farming and to the nutraceutical market for human consumption.

In this context, the annual production of dry microalgae biomass in the world is around 20.000 tons / year, which is still small little compared to the world production of agricultural products such as soybeans, sugar cane and corn that reach the levels of hundreds million tons per year.

Besides the direct use of live microalgae in aquaculture with emphasis on the genera Nannochloropsis, Chaetoceros and Thalassiosira or capsules for nutritional purpose with predominance of the genera Arthrospira, Dunaliella, Chlorella and Haematococcus could there be a universe of new bioproducts in expansion? The microalgae biomass containing intact cells has peculiar properties that are quite different from the properties of the aqueous emulsions formed after the rupture of the cell walls (promoted occasionally or intentionally) when the great majority of intracellular components are exposed and initiate a strong intermolecular interaction with water. The emulsions formed by hundreds of molecules have high stability due to their high protein content. As a rule, their composition entails molecular structures as diverse as phytosterols, enzymes, and carbohydrates, to name but a few classes of biochemicals belonging to a larger, rich and complex universe..

The ensemble presented in the form of an emulsion after being suitably characterized represents a bioproduct directly applicable as an additive in the pharmaceutical, cosmetic and food industries. After all, who would not want to use a natural, non-toxic, consistent, efficient and moisturizing sunscreen? The correct chemical separation of target molecules from this universe not yet fully known can give rise to compounds of fine chemistry $\beta$-caroten and lutein, high quality animal feed (protein residue) or biofuels as biodiesel and jet fuel. All are subject to research and development although some have already reached the commercial level.

The limits for obtaining and applying bioproducts from microalgae (Figure 1) reside in the lack of scientific knowledge about this universe and in the lack of economics involved in the processes of cultivation and refining of biomass-called biorrefine. (a)

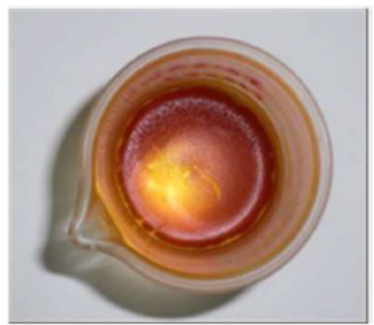

(b)

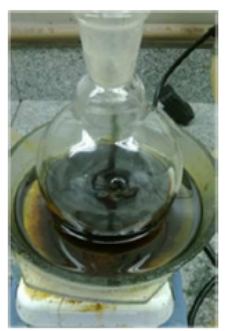

Figure 1: Mixture of carotenoids (a) and crude biodiesel (b) obtained from Chlorella sp. Joint project between Petrobras - CENPES and the Federal University of Rio de Janeiro - UFRJ. 
Many opportunities can arise from obtaining microalgae oil economically viable. Many opportunities can arise from obtaining microalgae oil economically viable. Special lubricants, jet fuel and biodiesel obtained from oil have been the subject of research investments over the last decade-mainly in the USA. Research institutes in China, USA and Europe have recorded an increase in their scientific output and their joint efforts through patents and publications on microalgae bioproducts which have a strong integration with the rational use of $\mathrm{CO}_{2}$.
Through a greater integration between the upstream processes involved in obtaining micro-algal biomass with $\mathrm{CO}_{2}$ biofixation and the downstream processes used to extract and obtain target molecules, it will be possible to achieve economics for the production of new molecules including advanced antibiotics.. With a growing variety of cultivated strains and innovative bioproducts, the creation of new consumer markets towards a low carbon economy would not be a huge surprise. 